\title{
Upregulated Expression and Function of VLA-4 Fibronectin Receptors on Human Activated T Cells in Rheumatoid Arthritis
}

\author{
Armando Laffón, ${ }^{*}$ Rosario García-Vicuña," Alicia Humbría, ${ }^{\star}$ Antonio A. Postigo, ${ }^{*}$ Angel L. Corbi, ${ }^{*}$ \\ Manuel O. de Landázuri, ${ }^{*}$ and Francisco Sánchez-Madrid* \\ Secciones de *Reumatología e ${ }^{\ddagger}$ Inmunología, Hospital de la Princesa, Universidad Autónoma de Madrid, Madrid, Spain
}

\begin{abstract}
The VLA-4 (CD49d/CD29) integrin is a cell surface receptor involved in the interaction of lymphoid cells with both extracellular matrix (ECM) and endothelial cells. We have investigated the expression and function of VLA-4 fibronectin (FN) receptors on $T$ cells localized in the inflammed synovium of patients with rheumatoid arthritis (RA). A high proportion of $T$ cells in both synovial membrane (SM) and synovial fluid (SF) expressed the activation antigens AIM (CD69) and gp95/85 (Ea2) as well as an increased number of VLA- $4 \alpha$ and $\beta 1$ adhesion molecules, as compared with peripheral blood (PB) $T$ cells from the same patients. Furthermore, the majority of these activated SF T cells were able to adhere to a 38-kD FN proteolytic fragment containing the connecting segment-1 (CS-1) specifically through VLA-4 receptors, whereas a significantly lower proportion of PB T cells displayed this capacity. Therefore, our results show that activated $T$ cells selectively localize at sites of tissue injury in RA disease and provide evidence for the in vivo regulation of the expression and function of the VLA-4 integrin. This regulatory mechanism may enable $T$ cells either to facilitate migration or to persist at sites of inflammation. (J. Clin. Invest. 1991. 88:546-552.) Key words: rheumatoid arthritis $\bullet$ activated $\mathbf{T}$ cells $\bullet$ fibronectin receptors
\end{abstract}

\section{Introduction}

The integrin family includes receptors for extracellular matrix $(\mathrm{ECM})^{1}$ components as well as receptors involved in cell-cell adhesive interactions (1-3). The $\beta 1$ integrin subfamily, also known as very late activation antigen (VLA) proteins contains at least six different $\alpha$ chains (VLA-1-VLA-6) associated with a common $\beta$ chain that function as receptors for ECM proteins such as collagen, fibronectin, and laminin (reviewed in reference 4). Recently, novel associations of $\alpha$ and $\beta$ subunits have

Address reprint requests to Francisco Sánchez-Madrid, Sección de Inmunología, Hospital de la Princesa, c/Diego de León 62, 28006 Madrid, Spain.

Received for publication 26 November 1990 and in revised form 16 April 1991.

1. Abbreviations used in this paper: AIM, activation inducer molecule; CS-1, connecting segment 1; ECM, extracellular matrix; FN, fibronectin; PB, peripheral blood; RA, rheumatoid arthritis; SF, synovial fluid; SM, synovial membrane; VCAM-1, vascular cell adhesion molecule; VLA, very late activation antigen.

J. Clin. Invest.

(c) The American Society for Clinical Investigation, Inc.

0021-9738/91/08/0546/07 \$2.00

Volume 88, August 1991, 546-552 been found, which expand the molecular and functional repertoire of VLA integrins (4).

VLA- 4 is a member of the $\beta 1$ integrins that is expressed by resting lymphocytes, monocytes, as well as by most $\mathrm{T}$ and $\mathrm{B}$ cell lines (4-7). Unlike other VLA members, the VLA-4 heterodimer has been implicated in cell-cell adhesion and antibodies against human VLA $\alpha 4$ chain inhibit the attachment of lymphocytes to high endothelial venule cells from Peyer's patches $(8,9)$. A VLA-4 ligand in activated endothelial cells has been recently discovered, vascular cell adhesion molecule (VCAM$1)$, that belongs to the Ig gene superfamily $(10,11)$. In addition, VLA-4 plays a role in both heterotypic adhesion between cytolytic T lymphocytes and B cell targets $(12,13)$, and homotypic leukocyte aggregations triggered by anti-VLA $\alpha 4$ antibodies $(14,15)$.

Similarly to the rest of VLA proteins, VLA-4 has also been involved in cell-ECM protein interactions. Thus, VLA-4 has been demonstrated to bind, in a RGD-independent manner, to the connecting segment 1 (CS-1) of fibronectin in both $\mathrm{T}$ and $\mathrm{B}$ cell lines $(10,16,17)$. Recent studies indicated that the expression of three different VLA heterodimers (VLA-4, VLA-5, and VLA-6) is regulated during $T$ cell maturation, because higher amounts of these integrins are found on memory (CD45RO+) $\mathrm{T}$ cells as compared with naive (CD45RO-) $\mathrm{T}$ cells (18).

As described for the LFA-1 leukocyte integrin (19), the constitutive expression of VLA receptors does not necessarily imply that they are functionally active. Thus, it has been described that the in vitro activation of $C D 4+T$ cells by phorbol esters and other stimuli induces VLA-mediated attachment to ECM proteins $(18,20)$.

We have addressed the question whether a regulated expression and function of the VLA-4 fibronectin receptors exists on $T$ cells which are activated in vivo in a pathological situation. Rheumatoid arthritis (RA) constitutes a human model of chronic articular inflammatory disease, where $T$ cells infiltrating the synovium may play an important role in the pathogenesis of this disease (21). The activation state of $\mathrm{T}$ lymphocytes can be investigated by means of the expression of activation molecules on the lymphocyte surface. It is well known that synovial fluid (SF) $T$ cells are activated, because they express HLA-DR and VLA-1 antigens, although they lack expression of IL-2 and transferrin receptor molecules (22-25).

In this study, we have more precisely determined the activation state of SF T cells by studying the expression of two novel lymphocyte activation antigens: AIM (CD69), the earliest inducible molecule on $\mathrm{T}$ cells, which is functionally associated to the proliferative process of $T$ cells (26), and gp95/85, an activation molecule similar in cell distribution and molecular characteristics to the previously described Ea2 activation antigen (27). The results here reported provide the first evidence for the regulation in vivo of the expression and function of the VLA-4 fibronectin receptors on activated $\mathrm{T}$ cells localized at sites of inflammation. 


\section{Methods}

Subjects. 10 patients with RA according to American College of Rheumatology criteria (28) were studied. Seven patients were female and three males. Their ages ranged between 21 and $76 \mathrm{yr}$ with a mean of $56.8 \mathrm{yr}$. All patients were taking nonsteroidal antiinflammatory drugs. In addition four of them were taking gold derivaties, one antimalarial drugs, one D-penicillamine, one methotrexate, and only one patient was under low doses of corticosteroid therapy. $T$ lymphocytes from six healthy donors were used as controls.

Preparation of purified T lymphocytes. PB and SF were collected at the same time in heparinized tubes, and mononuclear cells (MNC) were isolated by Ficoll-Hypaque gradient centrifugation (Pharmacia Fine Chemicals, Uppsala, Sweden). For purification of $T$ cells, adherent cells were removed from MNC by culturing on plastic petri dishes for $45 \mathrm{~min}$ at $37^{\circ} \mathrm{C}$, followed by passage through a nylon-wool column. Briefly, MNC were placed on a 600 -mg nylon-wool column preincubated for 30 min with RPMI 1640 (Flow Laboratories, Inc., Irvine, CA) supplemented with 10\% FCS (Gibco, Grand Island, NY), 2 mM glutamine, and $50 \mu \mathrm{g} / \mathrm{ml}$ penicillin per streptomycin. The MNC were then incubated on the column for $45 \mathrm{~min}$ at $37^{\circ} \mathrm{C}$. Cells were eluted with 20 $\mathrm{ml}$ of RPMI 1640. The purified T lymphocyte fractions contained $>90 \%$ of $\mathrm{CD} 3,<6 \%$ monocytes and $<1 \% \mathrm{~B}$ cells, as determined by expression of the CD3, Mo-2 (CD14), and B1 (CD20) antigens, respectively.

Monoclonal antibodies ( $\mathrm{mAb}$ ). The mAb directed against activation molecules in these studies were as follows: TP1/55 (anti-AIM/CD69) (26) and TP1/16 (anti-gp95/85), whose characterization will be described in detail elsewhere. Two different $\mathrm{mAb}$ were used to study the VLA complex: TS2/16, which recognizes the VLA $\beta 1$ subunit (29), and HP2/1 directed towards the VLA-4 $\alpha 4$ subunit $(6,14)$. The UCHL1 anti-CD45RO was kindly provided by Dr. P. C. Beverley (Imperial Cancer Research Foundation, London, UK).

The $\mathrm{mAb}$ used to assess the purity of $\mathrm{T}$ cell preparations were SPVT3b (anti-CD3) (30), Bear-1 (anti-CD1 1b) (31), and BC-1 (anti-CD20) (32). Anti-Mo-2 (CD14) was kindly provided by Dr. J. E. de Vries (Unicet Labs, Dardilly, France). Other mAb used as control was D3/9 mAb specific for the leukocyte common antigen (T200/CD45) (33). mAb X63 (IgGl), used as a negative control, is the Ig secreted by the mouse myeloma cell line P3-X63.

Flow cytometry analysis of $T$ cell surface activation antigens. Viable cells $\left(1-5 \times 10^{5}\right)$ were suspended in 50- $\mu$ l aliquots of PBS, $\mathrm{pH} 7.4$, containing $0.5 \%$ BSA. Specific mouse mAb $(1 \mu \mathrm{g}$ in $50 \mu \mathrm{l})$ was added and cells were incubated for $30 \mathrm{~min}$ at $4^{\circ} \mathrm{C}$, then washed twice and incubated with saturating amounts of fluorescein-conjugated $\mathrm{F}\left(\mathrm{ab}^{\prime}\right)_{2}$ goat anti-mouse Ig (Dakopatts, Copenhagen, Denmark). After three washes fluorescence was measured using an EPICS C flow cytometer (Coulter Electronics Inc., Hialeah, FL). The specific percentages of posi- tive cells for different $\mathrm{mAb}$ were obtained by subtracting the number of background cells that were nonspecifically stained with the myeloma $\mathrm{mAb} \times 63$ control.

Immunoperoxidase staining of tissue sections. Synovial samples were obtained from surgical synovectomy in RA patients, frozen in OCT (Ames Co., Miles Laboratories, Elkhart, IN) and stored at $-80^{\circ} \mathrm{C}$. The tissue sections were stained by an indirect immunoperoxidase method as described (34). Briefly, $4 \mu \mathrm{m}$ acetone fixed sections were sequentially incubated with $\mathrm{mAb}$ culture supernatants and peroxidaseconjugated rabbit anti-mouse Ig (Dakopatts, Cophenhagen, Denmark); each incubation was followed by three washes. The reaction was developed with Graham-Karnovsky medium containing $0.5 \mathrm{mg} / \mathrm{ml}$ of 3-3 diaminobenzidinetetrahydrochloride and hydrogen peroxide. Sections were counterstained with Carazi's hematoxilin followed by dehydration and mounting by routine methods.

Cell attachment analysis. Human fibronectin $38 \mathrm{kD}$ proteolytic fragment (from Dr. García-Pardo, Columbia University, New York) and type I collagen (Sigma Chemical Co., St. Louis, MO) were applied to 96-well flat bottom microtiter plates (Linbro; Flow Laboratories, Inc.) $\left(40 \mu \mathrm{g} / \mathrm{ml}, 0.1 \mathrm{ml} /\right.$ well) in CO3HNa $0.1 \mathrm{M}$ at $4^{\circ} \mathrm{C}$ overnight. Unbound binding sites were satured with RPMI 1640-1\% human seroalbumin for $2 \mathrm{~h}$ at $37^{\circ} \mathrm{C}$. Purified T cells isolated from peripheral blood and synovial fluid were added $(125,000$ cells/well) in $0.1 \mathrm{ml}$ of RPMI 1640 and incubated at $37^{\circ} \mathrm{C}$ and $5 \% \mathrm{CO}_{2}$. After 30 min plates were washed with RPMI 1640 several times and examined in an inverted microscope by at least two different observers. Within each well, cells from at least three different fields were counted and referred to a nonwashed well ( $100 \%$ or maximum binding). Each condition was performed on duplicate. In inhibition conditions, cells were incubated for 30 min at $4^{\circ} \mathrm{C}$ with $25 \%$ final volume of anti- $\alpha 4 \mathrm{HP} 2 / 1$ hybridoma culture supernatant and added to wells. In control conditions, cells were incubated with RPMI 1640 alone.

Statistical analysis. Statistical analysis was performed using Student's $t$ test.

\section{Results}

Previous studies have described the existence of subsets of activated T cells bearing the MHC class II and VLA-1 antigens infiltrating the synovium of patients with RA (22-24). We have determined more precisely the activation state of $T$ cells in both SF and peripheral blood (PB) compartments by studying the expression of two novel activation antigens AIM (CD69) and gp95/85 (Ea2). A remarkable high expression of both activation molecules was observed in SF T cells as compared to the weak expression of AIM and gp95/85 by PB T cells from same patients (Table I and Fig. 1). The expression of both AIM and

Table I. Expression of VLA-4 Integrin and Activation Antigens on SF and PB T Cells from RA Patients

\begin{tabular}{|c|c|c|c|c|c|c|c|c|}
\hline \multirow{3}{*}{ CD } & \multirow{3}{*}{$\begin{array}{c}\text { Antigen } \\
\text { specificity }\end{array}$} & \multirow{3}{*}{$\mathrm{mAb}$} & \multirow{2}{*}{\multicolumn{2}{|c|}{$\begin{array}{c}\text { Healthy donors }(n=6) \\
\text { PB }\end{array}$}} & \multicolumn{4}{|c|}{ RA Patients $(n=10)$} \\
\hline & & & & & PB & SF & PB & SF \\
\hline & & & $\% *$ & $M F I$ & & & & \\
\hline CD49d & VLA $-4 \alpha$ & HP2/1 & $51 \pm 15$ & $47 \pm 11$ & $42 \pm 18$ & $70 \pm 13^{\ddagger}$ & $45 \pm 23$ & $62 \pm 21^{11}$ \\
\hline $\mathrm{CD} 29$ & VLA $\beta 1$ & TS2/16 & $60 \pm 18$ & $56 \pm 16$ & $58 \pm 15$ & $82 \pm 10^{8}$ & $63 \pm 27$ & $85 \pm 17^{\ddagger}$ \\
\hline CD69 & AIM & TP1/55 & $3 \pm 2$ & $23 \pm 9$ & $10 \pm 8$ & $46 \pm 18^{\prime \prime}$ & $25 \pm 16$ & $49 \pm 17^{11}$ \\
\hline - & gp95/85 & TP1/16 & $26 \pm 10$ & $39 \pm 4$ & $30 \pm 13$ & $81 \pm 10^{\prime \prime}$ & $46 \pm 20$ & $83 \pm 22^{\prime \prime}$ \\
\hline - & & X63 & & $16 \pm 6$ & & & $16 \pm 11$ & $17 \pm 11$ \\
\hline
\end{tabular}

* Values are the percent of $\mathrm{T}$ cells positive for each antigen (mean $\pm \mathrm{SD}$ ) the specific percentages of positive cells mAb X63 control. (MFI) Mean fluorescence intensity (mean $\pm \mathrm{SD}$ ) values are expressed in a logarithmic scale. Statistical significance: ${ }^{\ddagger} P<0.01{ }^{8} P<0.05$; ${ }^{11} P<0.001$. 


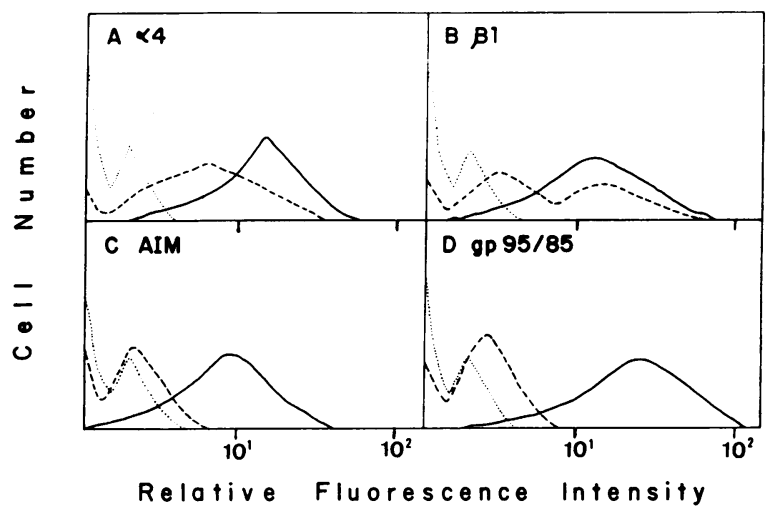

Figure 1. Expression of adhesion (VLA $\alpha 4$ and $\beta 1$ ) and activation (AIM and gp95/85 molecules by synovial fluid (SF) and peripheral blood (PB) T lymphocytes from a representative patient with rheumatoid arthritis (RA). Immunofluorescence flow cytometry analysis were performed on purified SF (solid line) or PB (dashed line) T lymphocytes obtained from a patient with RA. Cells were labeled with HP2/1 mAb (anti-VLA $\alpha 4$ ), TS2/16 mAb (anti-VLA $\beta 1$ ), TP1/55 $\mathrm{mAb}$ (anti-AIM), TP1/16 mAb (anti-gp95/85), and with the negative control X63 (dotted line). In a second step the cells were stained with a goat anti-mouse IgG-FITC.

gp95/85 activation antigens was very similar in PB T cells from either patients with RA or healthy donors (Table I). These results indicate that SF T cells represent in vivo activated $T$ lymphocytes selectively located at the site of tissue inflammation.

To determine the possible role of the VLA-4 integrin in T cells localized at the inflammed synovium, we first examined its expression and function on $\mathrm{T}$ cells from both SF and PB from patients with RA. As observed in Table I, flow cytometry studies demonstrated an increased expression of both VLA $\alpha 4$ and $\beta 1$ antigens in purified SF T cells as compared with that of purified PB T cells from same patients with RA, both in terms of percentage of positive cells and fluorescence intensity (compare flow cytometry profiles in Fig. 1). Levels of VLA-4 expres- sion on PB T cells from patients with RA were in the same range than those displayed by $\mathrm{PB} T$ cells from healthy donors (Table I). However, no significant changes in the expression levels of other cell surface antigens such as CD3 or CD45 were observed between SF and PB T cells (data not shown).

Similarly to SF T cells, the infiltrating CD3 + T lymphocytes located in the SM of RA patients (data not shown), also expressed the VLA-4 integrin and the CD69 activation antigen, as assessed by immunoperoxidase staining of synovial membrane (SM) tissue sections (Fig. 2). Most of the VLA-4+ T cell aggregates infiltrating SM were in the perivascular space although some scattered VLA-4+ T cells were also observed all over SM. The majority of the AIM+ T cells in SM also coexpressed the VLA-4 antigen as demonstrated by double immunostaining with anti-AIM and anti-VLA-4 mAb. Similar results were obtained with the anti-gp95/85 mAb (data not shown).

To determine the functional capacity of VLA-4 receptors expressed by these cells, adhesion studies to the $38-\mathrm{kD}$ FN fragment were performed with $\mathrm{T}$ cells purified from both $\mathrm{PB}$ and SF compartments of RA patients. The majority (79\%) of SF T cells were capable to adhere to plastic plates coated with the 38 kD FN fragment, whereas only a reduced percentage (30\%) of PB T cells displayed this capacity (Figs. 3 and 4). The percentages of PB T cells in RA patients that bound to $38 \mathrm{kD} \mathrm{FN}$ were in the same range to those found in PB T cells from healthy donors and correlated with the percents of lymphocytes bearing the CD45RO T cell memory marker (Fig. 3, and data not shown). Neither SF nor PB T cells bound to plates coated with collagen because they did not express detectable amounts of the VLA-2 collagen receptor (data not shown). Percentages of cell binding both in SF and PB correlated with the fractions of cells bearing the activation antigen gp $95 / 85$ and the CD45RO marker (Fig. 3).

The attachment of $\mathrm{T}$ cells from both PB and SF to the 38 kD FN fragment is illustrated in Fig. 4, $A$ and $C$, respectively. T cell binding to this ECM component was specifically mediated through VLA-4 receptors because the anti-VLA $\alpha 4 \mathrm{HP} 2 / 1$
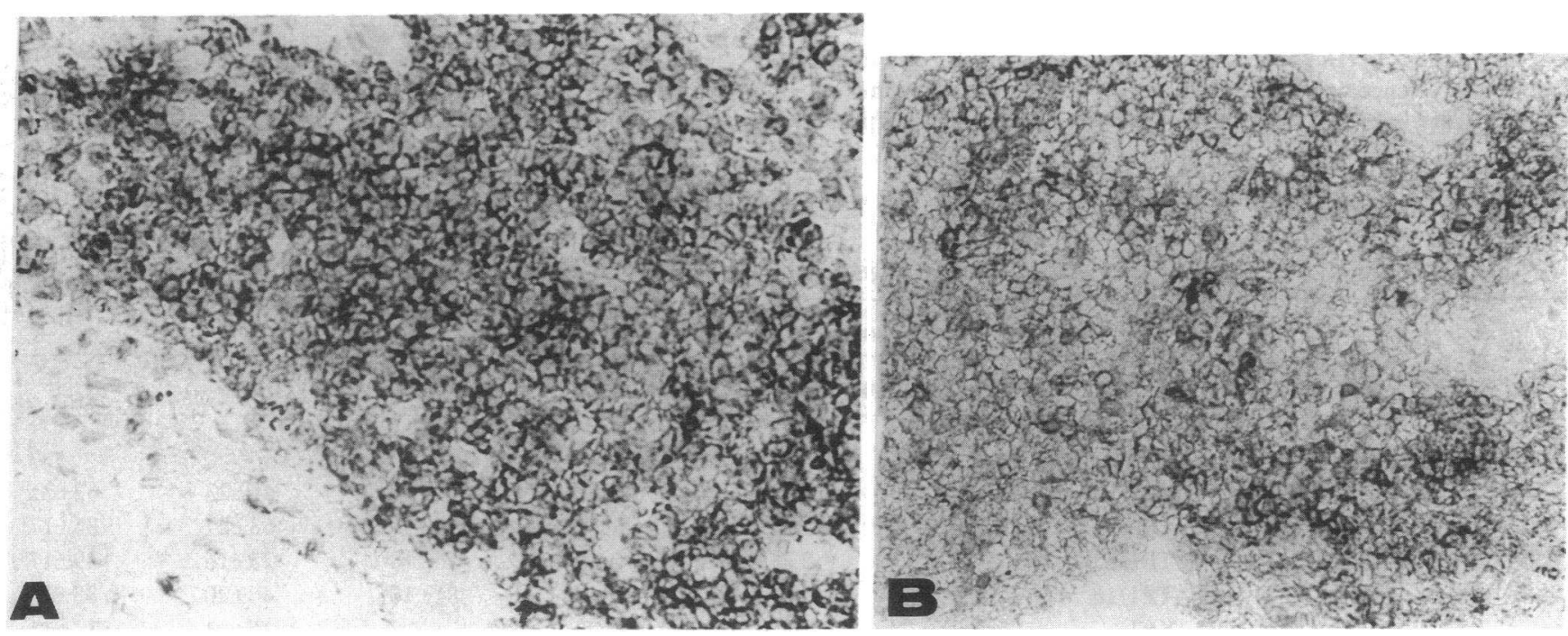

Figure 2. Immunoperoxidase staining of synovial tissue from one patient with RA, with anti-VLA-4 (HP2/1) $(A)$ and anti-AIM (TP1/55) $(B)$ mAb. Magnification, 400. 


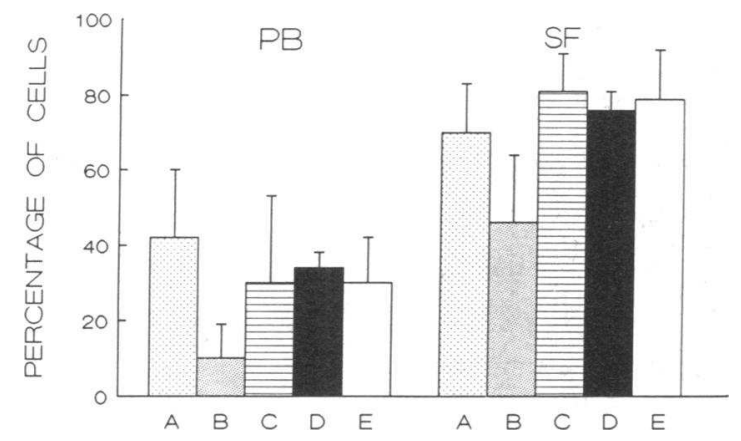

Figure 3. Comparison of the expression of VLA-4 (A), AIM (B), gp95/85 $(C)$, and CD45RO $(D)$ antigens and functional activity for binding to the 38-kD FN fragment $(E)$ of purified $\mathrm{T}$ cells from both peripheral blood $(P B)$ and synovial fluid $(S F)$. The values of cell expression of AIM and gp95/85 activation antigens and VLA-4 integrin are the average of 10 independent experiments obtained with cells from 10 different patients with RA. The values of CD45RO cell expression and cell adhesion are means of independent experiment with both SF and PB T cells from six different patients. Percentages of FN attached cells were $79 \% \pm 12$ for SF T cells and $30 \% \pm 11$ for PB T cells.

mAb almost completely abrogated cell attachment of either SF or PB T cells (Fig. 4, $B$ and $D$, respectively).

\section{Discussion}

In this study, results are reported demonstrating that $\mathrm{T}$ lymphocytes infiltrating both SF and SM compartments in patients with RA constitute an activated cell population bearing the CD69 and gp95/85 activation markers as well as displaying an enhanced expression and function of VLA-4 fibronectin receptor. Thus, we have found that the majority of these in vivo activated $T$ lymphocytes possesses functionally active VLA-4 fibronectin receptors enabling their interaction with an RGDindependent cell binding site on the $38 \mathrm{kD}$ proteolytic fragment of human plasma fibronectin. By contrast, a reduced fraction of $T$ cells from the PB compartment of same patients displayed this functional capacity.

Rheumatoid synovitis is characterized by the accumulation of mononuclear cells which have a tendency to form aggregates, particularly around blood vessels (35). The cells which infiltrate the perivascular space emigrate mainly from postcapillary venules. It is now generally accepted that $T$ cells locally infiltrating the rheumatoid synovial membrane play an important role in the pathogenesis of chronic inflammation of RA (21). A large fraction of the $T$ cells in the synovial infiltrate and SF appears to be in an activated state, as evidenced by the fact that a majority of these cells expresses activation markers, such as the HLA-DR antigen $(22,25)$. Furthermore, a subset of $T$ cells in the SF displays a low expression of the VLA-1 activation antigen, a member of the VLA integrin adhesion family, although they lack expression of IL-2 and transferrin receptor molecules (23-25). However, both HLA-DR and VLA-1 are not the more appropriate antigen markers to assess activation of $T$ cells because they are also expressed by a wide variety of cell types at both resting and activated states $(4,35)$.

In this sense, we have previously reported the structural and functional characterization of a novel human cell activation antigen, designated as "activation inducer molecule" (AIM), recently coded as CD69, that is rapidly expressed on $\mathrm{T}$ and $\mathrm{B}$ cells upon treatment with different stimuli $(26,36)$. Additionally, we have isolated a mAb specific for gp95/85, a dimeric structure weakly expressed on a small fraction of resting PB T cells whose expression is strongly induced on activated lymphoid cells. The biochemical and functional characteristics of gp95/85 are similar to those of the previously described for the Ea2 activation antigen (27), although comparative studies will be required to ascertain whether both $\mathrm{mAb}$ are recognizing identical molecular structures.

We have found a strong expression of both AIM (CD69) and gp95/85 activation antigens on SF and SM T cells from all RA patients, compared to their absence or low expression by PB T cells from either same patients or healthy donors. These findings indicate that a large fraction of $T$ cells infiltrating the rheumatoid SM and SF are in an activated state. Similarly, an activated $T$ cell subset bearing the $\mathrm{CD} 69$ activation antigen has been recently reported in the lymphocyte infiltrate of chronic inflammatory liver diseases (37).

The percentages of RA PB T cells displaying functional capacity to adhere to $38-\mathrm{kD}$ FN are within the same range of those previously described in PB T cells from healthy donors and correspond to the CD45RO+ memory T cell subset (18). The CD45RO+ PB T cells have been reported to express higher amounts of different adhesion receptor molecules than the CD45RO- naive T cells (38), correlating with their enhanced functional adhesive capacity to ECM protein components (18). We have also found that most of activated $T$ cells in SF bear the CD45RO marker as described by other authors (39), and in agreement with in vitro studies showing the acquisition of CD45RO antigen upon $\mathrm{T}$ cell activation $(38,40)$.

The VLA-4 integrin plays a dual role as a receptor involved in both cell-cell and cell-ECM adhesive interactions through the two known ligands VCAM-1 and FN. Our data reveal that activated $T$ cells found in SF of patients with RA expressed higher amounts of VLA-4 fibronectin receptor molecules than PB T cells, correlating with their enhanced binding activity to the $38-\mathrm{kD}$ FN fragment specifically mediated by VLA-4 integrin.

There are two possible explanations for the differences in the adhesion activities found between SF and PB T cells to the 38-kD FN component. First, the overexpression of VLA-4 molecules of SF T cells, probably due to the activation process, could be responsible of the enhancement of VLA-4-mediated ECM binding. A second possibility is that cell activation process undergone by SF T cells induces functionally active forms of VLA-4 integrins by conformational changes on these molecules. This fact could reflect an in vivo situation of what it has been described in in vitro activation for different integrin molecules from the $\beta 1, \beta 2$, and $\beta 3$ families. In this sense, conformational changes occurring during cell activation have been suggested for gpIIb/IIIa, Mac-1 and LFA-1 integrins resulting in active forms enabling their respective receptor-ligand interactions $(19,41-45)$. Very recently, the enhanced binding activity of some VLA members to their respective ECM protein ligands has been described on peripheral blood CD4 $+\mathrm{T}$ cells upon activation with phorbol esters or CD3 and CD2 antibodies (18, 20). Finally, a combination of both explanations could also be possible. However, the nature of biochemical events responsi- 

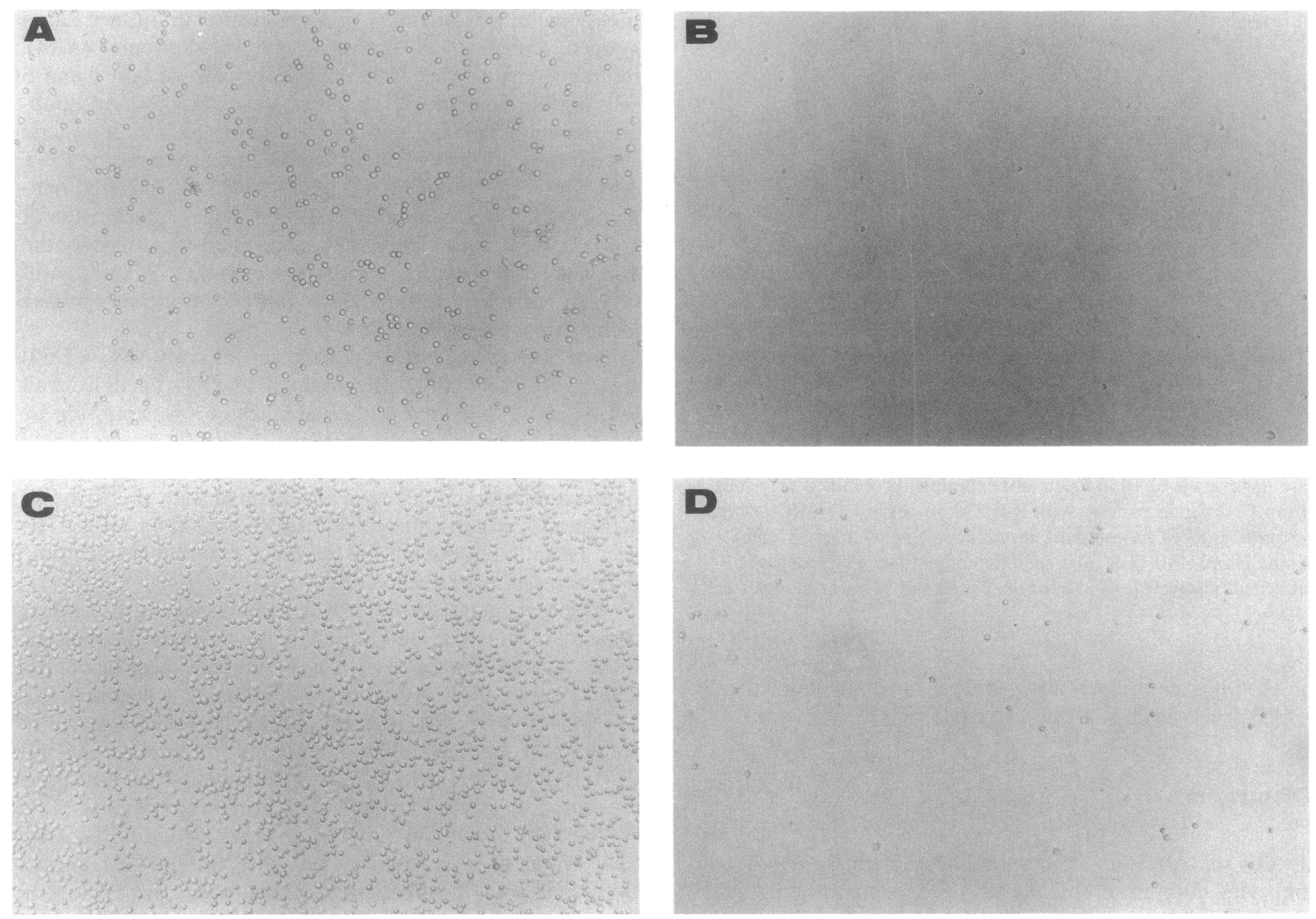

Figure 4. Binding of $\mathrm{T}$ cells from $\mathrm{PB}(A, B)$ and $\mathrm{SF}(C, D)$ of patients with RA to a 38-kD FN fragment either in the absence $(A, C)$ or the presence $(B, D)$ of anti-VLA $4 \alpha \mathrm{HP} 2 / 1 \mathrm{mAb}$.

ble of these putative conformational changes still remains to be elucidated. It has been proposed that phosphorylation of specific residues plays a role in the regulation of the functional states of integrin molecules $(46,47)$.

The functional significance of the presence of in vivo activated $T$ cells bearing functionally active VLA-4 FN receptors locally infiltrating inflamed synovium of RA patients remains uncertain. It is tempting to speculate about a role of VLA-4 in the pathogenesis of RA. Thus, it could be suggested that VLA-4 may direct the migration of these cells to sites of inflammation where a high concentration of fibronectin exists. In this sense, fibronectin has been detected in higher levels in SF from patients with RA than in plasma and other SF $(48,49)$. Rised levels of FN in SF from rheumatoid joints may be possibly accounted for a restricted and localized increase in the production of this protein by synovial cells at the site of the articular disease. It is therefore possible that the local production of FN within affected joints may influence the continuance of arthritis depending on the amounts synthesized by the stimulated synovial tissue $(50,51)$. Conceivably, these $T$ cells have undergone an antigen-dependent activation process as deduced from their activated phenotype and have a increased number of functional FN receptors that facilitate their migration through synovial tissue towards gradients of higher fibronectin concen- tration. Alternatively, the adherence of cells to FN through VLA receptors could represent a mechanism of persistency of $T$ cells at sites of inflammation. Whether a similar regulatory mechanism in operating in other VLA receptors also expressed by $T$ cells such as VLA- 5 and VLA- 6 and its possible role in the RA pathogenesis remains to be elucidated.

The VLA-4 molecule may play an additional role in lymphocyte-endothelial cell interactions through its ligand VCAM-1, $(10,52)$. The relevance of VLA-4 in the lymphocyte entry to the inflammed synovium still remains undetermined. In the early stages of RA, coincident with the neovascularization of the SM, circulating lymphocytes adhere to endothelium in postcapillary synovial venules. $T$ cells bearing CD45RO marker have been reported to adhere better to endothelial cells than CD45RO- cells (53) and thus, gain access more easily to the synovial membrane (54). Further studies are required to determine whether a functional regulation of VLA-4/VCAM-1 interaction may exist on SF T cells, expressing the CD45RO marker, in a similar fashion to that here described for VLA-4/ FN. Cell binding assays of both SF and PB T cells from patients with RA to VCAM-1 transfectant cells as well as to endothelial cells from RA synovial tissue will be required to ascertain the role of VLA-4 in the lymphoid traffick to inflamed synovium in RA disease. 


\section{Acknowledgments}

We are indebted to C. López-Elzaurdia for her advice with immunohistochemical technique. We acknowledge the secretarial assistance of Mrs. A. Vallejo.

This work was supported by a grant from INSALUD (FISS 90/ 0096) and a grant from Fundación Ramón Areces (F. SánchezMadrid).

\section{References}

1. Hynes, R. O. 1987. Integrins: a family of cell surface receptors. Cell. 48:549-554.

2. Hemler, M. E. 1988. Adhesive proteins receptors on hematopoietic cells. Immunol. Today. 41:109-513.

3. Springer, T. A. 1990 . Adhesion receptors of the immune system. Nature (Lond.). 346:425-434.

4. Hemler, M. E. 1990. VLA proteins in the integrin family: structures, functions and expression on leukocytes. Annu. Rev. Immunol. 8:365-400.

5. De Strooper, B., B. Van der Schueren, M. Jaspers, M. Saison, M. Spaeden, F. Van Leuven, H. Van der Bughe, and J. J. Cassiman. 1989. Distribution of the $\beta 1$ subgroup of the integrins in human cells and tissues. J. Histochem. Cytochem. 37:299-307.

6. Sánchez-Madrid, F., M. O. de Landázuri, G. Morago, M. Cebrián, A Acevedo, and C. Bernabeu. 1986. A novel polypeptide association within the VLA molecular complex: cell distribution and biochemical characterization. Eur. J. Immunol. 16:1343-1349.

7. Hemler, M. E., M. J. Elices, C. Parker, and Y. Takada. 1990. Structure of the integrin VLA-4 and its cell-cell and cell-matrix adhesion functions. Immunol. Rev. 114:45-65.

8. Holzmann, B., and I. L. Weissman. 1989. Integrin molecules involved in lymphocyte homing to Peyer's patches. Immunol. Rev. 108:45-62.

9. Holzmann, B., B. W. McIntyre, and I. L. Weissman. Identification of a murine Peyer's patch-specific lymphocyte homing receptor as an integrin molecule with an $\alpha$ chain homologous to human VLA-4 $\alpha$. Cell. 56:37-46.

10. Elices, M. J., L. Osborn, Y. Takada, C. Crouse, S. Luhowskyi, M. E. Hemler, and R. R. Lobb. 1990. VCAM-1 on activated endothelium interacts with the leukocyte integrin VLA-4 at a site distinct from the VLA-4/fibronectin binding site. Cell. 60:577-584.

11. Osborn, L., R. Hession, C. Tizard, C. Vasallo, S. Luhowskyi, G. Chirosso, and R. R. Lobb. 1989. Direct expression of vascular cell adhesion molecule 1, a cytokine-induced endothelial protein that binds lymphocytes. Cell. 59:12031211.

12. Clayberger, C., A. M. Krensky, B. W. McIntyre, T. S. Koller, P. Parham, F. Brodsky, D. J. Linn, and E. L. Evans. 1989. Identification and characterization of two novel lymphocyte function- associated antigens, L24 and L25. J. Immunol. 138:1510-1514.

13. Takada, Y., M. J. Elices, C. Crouse, and M. E. Hemler. 1989. The primary structure of the $\alpha 4$ subunit of VLA-4: homology to other integrins and a possible cell-cell adhesion function. EMBO (Eur. Mol. Biol. Organ.) J. 8:1361-1368.

14. Campanero, M. R., R. Pulido, M. A. Ursa, M. Rodríguez-Moya, M. O. de Landázuri, and F. Sánchez-Madrid. 1990. An alternative leukocyte homotypic adhesion mechanism, LFA-1/ICAM-1 independent, triggered through the human VLA-4 integrin. J. Cell Biol. 110:2157-2165.

15. Bednarczyk, J. L., and T. W. McIntyre. 1990. A monoclonal antibody to VLA-4 $\alpha$ chain (CDw 49d) induces homotypic lymphocyte agregation. J. Im munol. 144:777-784.

16. Wayner, E. A., A. García-Pardo, J. A. Humphries, J. A. MacDonald, and W. G. Carter. 1989. Identification and characterization of the T lymphocyte adhesion receptor for an alternative cell attachment domain (CS-1) in plasma fibronectin. J. Cell Biol. 109:1321-1330.

17. García-Pardo, A., E. A. Wayner, W. G. Carter, and O. C. Ferreira. 1990 Human $B$ lymphocytes define an alternative mechanism of adhesion to fibronectin. The interaction of the $\alpha 4 \beta 1$ integrin with the LHGPEILDVPST sequence of III CS is sufficient to promote cell attachment. J. Immunol. 114:3361-3366.

18. Shimizu, Y., G. A. Van Seventer, K. J. Horgan, and S. Shaw. 1990. Regulated expression and binding of three VLA $(\beta 1)$ integrin receptors on T cells. Nature (Lond.). 345:250-253.

19. Dustin, M. L., and T. A. Springer. 1989. T-Cell receptor cross-linking transiently stimulates adhesiveness through LFA-1. Nature (Lond.). 341:619624.

20. Shimizu, Y., G. A. van Seventer, K. J. Horgan, and S. Shaw. 1990. Costimulation of proliferative response of resting CD4 $+\mathrm{T}$ cells by the interaction of VLA-4 and VLA-5 with fibronectin or VLA-6 with laminin. J. Immunol. 145:659-667.

21. Cavender, P., D. Haskard, C.-L. Yu, P. Miossec, M. Oppenheimer-Marks, and M. Ziff. 1987. Pathways to chronic inflammation in Rheumatoid synovitis. Fed. Proc. 46:113-117.

22. Burmester, G. R., D. T. I. Yu, A. M. Irani, H. G. Kunkel, and R. J. Winchester. 1981. Ia + T cells in synovial fluid and tissues of patients with rheumatoid arthritis. Arthritis Rheum. 24:1370-1376.

23. Hemler, M. E., D. Glass, J. S. Coblyn, and J. G. Jacobson. 1986. Very late activation antigens on rheumatoid synovial fluid $T$ lymphocytes: association with stages of $T$ cell activation. J. Clin. Invest. 78:696-702.

24. Laffón, A., F. Sánchez-Madrid, M. O. de Landázuri, A. Ariza, C. Ossorio, and $P$. Sabando. 1989. Very late activation antigen on synovial fluid $T$ cells from patients with rheumatoid arthritis and other rheumatic diseases. Arthritis Rheum. 32:386-392.

25. Cush, J. J., and P. E. Lipsky. 1988. Phenotypic analysis of synovial tissue and peripheral blood lymphocytes isolated from patients with rheumatoid arthritis. Arthritis Rheum. 10:1230-1238.

26. Cebrián, M., E. Yagüe, M. Rincón, M. López-Botet, M. O. de Landázuri and F. Sánchez-Madrid. 1988. Triggering of T cell proliferation through AIM, an activation inducer molecule on activated human lymphocytes. J. Exp. Med. 168:1621-1637.

27. Newman, W., V. A. Fanning, P. E. Rao, E. F. Westberg, and E. Patten. 1986. Early events in lymphocyte activation as defined by three new monoclonal antibodies. J. Immunol. 137:370-378.

28. Arnett, F. C., S. M. Edworthy, D. A. Bloch, D. J. McShane, J. F. Fries, N. S. Cooper, L. A. Healey, S. R. Kaplan, M. H. Liang, H. S. Luthra, T. A. Medsger, D. M. Mitchell, D. H. Neustadt, R. S. Pinals, J. G. Schaller, J. T. Sharp, R. L. Wilder and G. G. Hunder. 1988. The American Rheumatism Association 1987: revised criteria for the classification of rheumatoid arthritis. Arthritis Rheum. 31:315-324.

29. Hemler, M. E., F. Sánchez-Madrid, T. J. Flotte, A. M. Krensky, S. J. Burakoff, A. K. Bhan, T. A. Springer, and J. L. Strominger. 1984. Glycoproteins of 210,000 and 130,000 m.w. on activated T cells: cell distribution and antigenic relation to components on resting cells and T cell lines. J. Immunol. 132:30113018.

30. Spits, H. H. Yssel, J. Leewenberg and J. E. de Vries. 1985. Antigen-specific cytotoxic $T$ cell and antigen-specific proliferating $T$ cell clones can be induced to cytolytic activity by monoclonal antibodies against T3. Eur. J. Immunol. 15:88-91.

31. Keizer, G. D., J. Borst, and C. G. Figdor, H. Spits, F. Miedema, C. Terhorst, and J. E. de Vries. 1985. Biochemical and functional characteristics of the human leukocyte membrane antigen family LFA-1, Mol and p150,95. Eur. J. Immunol. 15:1142-1147.

32. Anegón, I., R. Vilella, T. Gallart, C. Kuturi, L. Borche, J. Mila, and J. Vives. 1986. B-C1, B-C2, B-C3: monoclonal antibodies against B cell differentiation antigens. In E. L. Reinherz, B. F. Haynes, L. Nadler, I. D. Berstein, editors. Leukocyte Typing II. Springer-Verlag, New York. 121-124.

33. Pulido, R., M. Cebrián, A. Acevedo, M. O. de Landázuri, and F. SánchezMadrid. 1988. Comparative biochemical and tissue distribution of four distinct CD45 antigen specificities. J. Immunol. 140:3851-3857.

34. Graham, R. C., and M. I. Karnovsky. 1986. The early stages of absortion of injected horseradish peroxidase in the proximal tubules of mouse kidney. Ultrastructural cytochemistry by a new technique. J. Histochem. Cytochem. 14:291-298.

35. Ishikawa, H., and M. Ziff. 1976. Electron microscopic observations of immunoreactive cells in the rheumatoid synovial membrane. Arthritis Rheum. 19:1-7.

36. Sánchez-Mateos, P., M. Cebrián, A. Acevedo, M. López-Botet, M. O. de Landázuri, and F. Sánchez-Madrid. 1989. Expression of a gp 33/27,000 MW activation inducer molecule (AIM) on human lymphoyd tissues. Induction of cell proliferation on thymocytes and B lymphocytes by anti-AIM antibodies. Immunology. 68:72-79.

37. García-Monzón, C., R. Moreno-Otero, J. M. Pajares, A. García-Sánchez M. López-Botet, M. O. de Landázuri, and F. Sánchez-Madrid. 1990. Expression of a novel $\mathrm{T}$ cell activation antigen (AIM) on CD8+ T lymphocytes in the inflammatory infiltrate in virus-related chronic active hepatitis. Gastroenterology. 98:126-132.

38. Sanders, M. E., M. W. Makgoba, S. O. Sharrow, D. Stephany, T. A. Springer, H. A. Young, and S. Shaw. 1988. Human memory T lymphocytes express increased levels of three cell adhesion molecules (LFA-3, CD2, and LFA1) and three other molecules (UCHL1, CDw29, and Pgp-1) and have enhanced IFN $\tau$ production. J. Immunol. 140:1401-1407.

39. Pitzalis, C., G. Kingsley, J. Murphy, and G. Panayi. 1987. Abnormal distribution of helper-inducer and suppressor-inducer $T$ lymphocyte subsets in the rheumatoid joint. Clin. Immunol. Immunopathol. 45:252-258.

40. Akbar, A. N., L. Terry, A. Timms, P. C. L. Beverley, and G. Janossy. 1988. Loss of CD45R and gain of UCHL1 reactivity is a feature of primed T cells. $J$. Immunol. 140:2171-2178.

41. Altieri, D. C., and T. S. Edgington. 1988. The saturable high affinity association of factor $\mathrm{X}$ to ADP-stimulated monocytes defines a novel function of the Mac-1 receptor. J. Biol. Chem. 263:7007-7015. 
42. Detmers, P. A., S. D. Wright, E. Olsen, B. Kimball, and Z. A. Cohn. 1987. Aggregation of complement receptors on human neutrophils in the absence of ligand. J. Cell Biol. 105:1137-1145.

43. Ginsberg, M. H., J. C. Loftus, and E. F. Plow. 1988. Cytoadhesins, integrins and platelets. Thromb. Haemostasis. 59:1-6.

44. Phillips, D. R., I. F. Charo, L. V. Parise, and L. A. Fitzgerald. 1988. The platelet membrane glycoprotein IIb/IIIa complex. Blood. 71:831-843.

45. Wright, S. S., S. M. Levin, M. T. C. Jong, Z. Chad, and L. G. Kabbash. 1983. CR3 (CD1 lb/CD18) expressed one binding side for Arg-Gly-Asp-containing peptides and a second side for bacterial lipopolysaccharide. J. Exp. Med. 169:175-183.

46. Chatila, T. A., R. S. Geha, and M. A. Arnaout. 1989. Constitutive and stimulus-induced phosphorylation of CD11/CD18 leukocyte adhesion molecules. J. Cell Biol. 109:3435-3444.

47. Shaw, L. M., J. M. Messier, and A. M. Mercurio. 1990. The activation dependent adhesion of macrophages to laminin involves cytoskeletal anchoring and phosphorylation of the $\alpha 6 \beta 1$ integrin. J. Cell Biol. 110:2167-2174.

48. Carsons, S., M. W. Mosesson, and H. S. Diamond. 1981. Detection and quantitation of fibronectin in synovial fluid from patients with rheumatic diseases. Arthritis Rheum. 24:1261-1267.

49. Clemmensen, I., and R. D. Andersen. 1982. Different molecular forms of fibronectin in rheumatoid synovial fluid. Arthritis Rheum. 25:25-31.

50. Herbert, K. E., J. S. Coppock, A. M. Griffith, A. Williams, M. W. Robinson, and D. L. Scott. 1987. Fibronectin and immune complexes in rheumatoid diseases. Ann. Rheum. Dis. 46:734-740.

51. Scott, D. L., A. C. Wainwright, K. W. Walton, and N. Williamson. 1981. Significance of fibronectin in rheumatoid arthritis and ostheoarthrosis. Ann. Rheum. Dis. 40:142-153.

52. Osborn, L. 1990. Leukocyte adhesion to endothelium in inflammation. Cell. 62:3-6.

53. Pitzalis, C., G. Kingsley, D. Haskard, and G. Panayi. 1988. The preferen tial accumulation of helper inducer $T$ lymphocytes in inflammatory lesions evidence for regulation by selective endothelial and homotypic adhesion. Eur. J. Immunol. 18:1397-1404.

54. Ziff, M. 1989. Role of endothelium in chronic inflammation. Springer Semin. Immunopathol. 11:199-214. 